\title{
A study of specific absorption rate in human head due to electromagnetic exposure to $4 \mathrm{G}$ signals
}

\author{
Siti Rokiah Abdul Mutalik ${ }^{1}$, Mohd Hafizuddin Mat' ${ }^{2}$, Muzammil Jusoh ${ }^{3}$, A. W. N. Husna \\ ${ }^{1,3}$ School of Computer and Communication Engineering, Universiti Malaysia Perlis (UniMAP), Malaysia \\ ${ }^{2}$ Centre for Diploma Studies, Universiti Malaysia Perlis (UniMAP), Malaysia \\ ${ }^{4}$ School of Electrical Systems Engineering, Universiti Malaysia Perlis (UniMAP), Malaysia
}

\section{Article Info \\ Article history: \\ Received Aug 25, 2018 \\ Revised Nov 26, 2018 \\ Accepted Dec 13, 2018}

\section{Keywords:}

Biolectromagnetic

Electromagnetic field

Electromagnetic fields effects

In-body communications

SAR

Specific absorption rate

\begin{abstract}
This paper presents a numerical analysis of the specific absorption rate in SAM phantom exposed to electromagnetic field. A two set dipole antenna operating with $1800 \mathrm{MHz}$ and $2600 \mathrm{MHz}$ were placed parallel to the z-axis and rotated in clockwise from $0^{\circ}$ (vertical) to $180^{\circ}$ in steps of $30^{\circ}$ to investigate the effect of frequency and polarization. The maximum average of 1 gram and 10gram of tissue have been presented to show the effect of SAR in SAM phantom model. A comparison of the mass average SAR in head shows the $1 \mathrm{~g}$ of SAR at $2600 \mathrm{MHz}$ is double to $1800 \mathrm{MHz}$ frequency. While for $10 \mathrm{~g}$ of SAR, slightly different for both $1800 \mathrm{MHz}$ and $2600 \mathrm{MHz}$.
\end{abstract}

\section{Corresponding Author:}

Mohd Hafizuddin Mat,

Centre for Diploma Studies,

Universiti Malaysia Perlis (UniMAP),

S2-L1-26, Kampus UniCITI Alam Sg. Chuchuh,

Chuchuh, 02100 Padang Besar (U), Perlis, Malaysia.

Email: hafizuddinmat@unimap.edu.my

\section{INTRODUCTION}

Nowadays, human health has been topically a hefty portion due to cell phones impacts. Since cell phone are increasingly sophisticated, there has been both scientific and public remark that the human health can be unfavorably influence by radiation from cell phones [1]-[11]. Some researcher has discussed that the coupling of electromagnetic field emitted by cell phones might cause impact to human head because as known, cell phones can produced a proportion of radio frequency energy that can be absorbed in human head [4], [11], [12]. In Cooper's research [7] concludes that metallic implant in head can increased the SAR value. While Whittow's [11], [12], the specific absorption rate (SAR) level can be affected by the jewellery and metallic ring in human head [13], [14].

Specific absorption is defined as the quotient of the incremental energy (dE) absorbed by an incremental mass $(\mathrm{dm})$ contained in a volume $(\mathrm{dV})$ of a given density $(\rho)$. However, specific absorption rate (SAR) is defined as the rate of energy (dE) absorbed or dissipated in an incremental mass (dm) contained in an incremental volume (dV) of a given density $(\rho)$ [1]-[3], [5]-[10], [15]-[31]. Mathematically, SAR can be expressed in watt per kilogram $(\mathrm{W} / \mathrm{kg})$ as

$$
S A R=\frac{d}{d t}\left(\frac{d E}{d m}\right)=\frac{d}{d t}\left(\frac{d E}{\rho d V}\right)
$$


However, the SAR for specifying the radiofrequency absorption by tissue can be calculated at any location in the tissue from the electric field (E) as shown below:

$$
S A R=\frac{\sigma|E|^{2}}{\rho}
$$

Where :

$\sigma=$ Conductivity $(\mathrm{S} / \mathrm{m})$

$\rho=$ Mass density $\left(\mathrm{kg} / \mathrm{m}^{3}\right)$

$\mathrm{E}=\operatorname{root}$ mean square $(\mathrm{rms})(\mathrm{V} / \mathrm{m})$

Averaged SAR limits has been recommended by International Commission on Non-Ionizing Radiation Protection (ICNIRP) for communication devices that the SAR should be less than $2 \mathrm{~W} / \mathrm{kg}$ for averaged $10 \mathrm{~g}$ mass of tissue $\left(\mathrm{SAR}_{10 \mathrm{~g}}\right)$ [32]-[39]. However, for $1 \mathrm{~g}$ of tissue $\left(\mathrm{SAR}_{1 \mathrm{~g}}\right)$, the Institute of Electrical and Electronics Engineers (IEEE) has sets a slightly stricter limit value which is $1.6 \mathrm{~W} / \mathrm{kg}$ [40].

In this paper, investigation on the effect of SAR in human head at ear model with different frequency and polarization. Since the possible uses of cell phones near to ear can be effect on human health has been topical over the last several years because communication devices which is cell phones produces radiofrequency energy that can be effect to human.

\section{RESEARCH METHOD}

\subsection{Simulation and Radiofrequency Exposure}

The modelling and calculations of EM fields were carried out by using Computer Simulation Technology Microwave Studio (CST MWS). Time domain Solver (TDM) has been used to simulate the design before the Specific Absorption Rate (SAR) been calculated. By using IEEE/IEC 62704-1 averaging method, the reference power for this experiment are defined as output power at $1 \mathrm{~W}$ (rms). The head tissue density has been defined as $1000 \mathrm{~kg} / \mathrm{m}^{3}$.

These research were carried out to isolate the relative effect of the RF exposure to human head with different frequencies and polarizations. In this project, dipole antennas been chosen as a standardized source with a single polarization since the are many different RF sources. Therefore, the simulation can be clearly being analyze. Two antennas were used by considered each antenna with $1800 \mathrm{MHz}$ and $2600 \mathrm{MHz}$ frequency, respectively. The feed point of antennas was located in a $2 \mathrm{~mm}$ air gap between the dipole halves constructed by using perfect electric conductors (PEC). The diameter for both antenna has fixed to $1.8 \mathrm{~mm}$. Figure 1 show the diagram of dipole antenna.

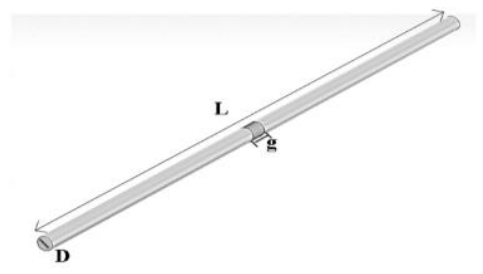

Figure 1. Diagram of dipole antenna design

where :

$\mathrm{D}=$ diameter of wire $(\mathrm{mm})$

$\mathrm{g}=\operatorname{air} \operatorname{gap}(\mathrm{mm})$

$\mathrm{L}=$ length of half wave dipole $(\mathrm{mm})$

$\mathrm{a}=$ Acceleration of the object

A half wave dipole antenna with $1800 \mathrm{MHz}$ and $2600 \mathrm{MHz}$ was designed with length of half wave dipole, $\mathrm{L} 74.78 \mathrm{~mm}$ and $51.5 \mathrm{~mm}$, respectively.

\subsection{Head Phantom}

Specific Anthropomorphic Mannequin (SAM) phantom head has been used as the head model in this paper because it is the standard head for SAR investigation. In human head shaped phantom, has a shell filled with a tissue simulating liquid (TSL). The TSL are represent the average dielectric properties of the 
human head. The outer shell of the SAM phantom head has been fixed relative permittivity with 3.7 and $0.00016 \mathrm{~S} / \mathrm{m}$ for electrical conductivity. The dielectric properties of the TSL for both $1800 \mathrm{MHz}$ and $2600 \mathrm{MHz}$ are shown in Table 1.

Table 1. The Dielectric Properties of TSL for 1800MHz and 2600MHz Frequency

\begin{tabular}{ccc}
\hline Frequency $(\mathrm{MHz})$ & Relative Permittivity & Electrical conductivity $(\mathrm{S} / \mathrm{m})$ \\
\hline 1800 & 40.0 & 1.4 \\
2600 & 39.0 & 1.96 \\
\hline
\end{tabular}

Hence, the SAM phantom head model were attached with dipole antennas. The antennas were designed for both $1800 \mathrm{MHz}$ and $2600 \mathrm{MHz}$ with $2 \mathrm{~mm}$ air gap, g, diameter of wire, D $1.8 \mathrm{~mm}$. While for length of half wave dipole, $\mathrm{L}$ for $1800 \mathrm{MHz}$ and $2600 \mathrm{MHz}$ frequency are $74.78 \mathrm{~mm}$ and $51.5 \mathrm{~mm}$, respectively. The dipole antenna located with $0.1 \mathrm{~mm}$ between dipole antennas and ear of SAM phantom are fixed.

Figure 2 show the SAM phantom head model attached with dipole antenna in $0^{\circ}$. The dipole antenna is set in vertically to head and will be rotate until $180^{\circ}$ in steps of $30^{\circ}$.

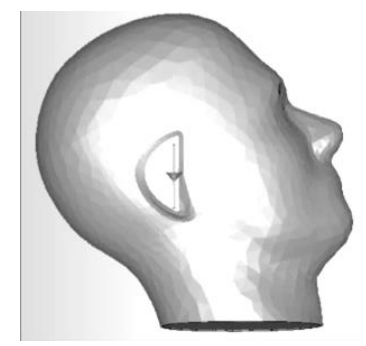

Figure 2. The SAM phantom head model with dipole antenna

\section{RESULTS AND ANALYSIS}

In order to study the effect of $1800 \mathrm{MHz}$ and $2600 \mathrm{MHz}$ frequency to human head, the maximum mass averaged for $1 \mathrm{~g}$ and $10 \mathrm{~g}$ of SAR in head was investigated. The dipole antenna was chosen in this project is $1800 \mathrm{MHz}$ and $2600 \mathrm{MHz}$ frequency. The frequency was commonly in used in many countries including Malaysia.

Firstly, parallel to $\mathrm{z}$-axis $\left(0^{\circ}\right)$ the dipole antenna will be rotated in clockwise from $0^{\circ}$ (vertical) to $180^{\circ}$ in steps of $30^{\circ}$ (while in $90^{\circ}$ is parallel to the y-axis). The variations of dipole antenna angle were to investigate the worst case situation. In this paper, $1 \mathrm{~W}$ has been fixed as output power.

Figure 3 and 4 shows the result for both $1800 \mathrm{MHz}$ and $2600 \mathrm{MHz}$ frequency for $\mathrm{SAR}_{1 \mathrm{~g}}$ respectively. The peak average $\mathrm{SAR}_{1 \mathrm{~g}}$ was at $60^{\circ}$ for $1800 \mathrm{MHz}$ while for $2600 \mathrm{MHz}$ at $120^{\circ}$ with $28.364 \mathrm{~W} / \mathrm{kg}$ and $41.9741 \mathrm{~W} / \mathrm{kg}$ respectively. However, at $30^{\circ}$ to $120^{\circ}$ has little effect on mass averaged SAR for $1800 \mathrm{MHz}$ frequency same as at $2600 \mathrm{MHz}$ frequency, the effect to average mass SAR has little effect.

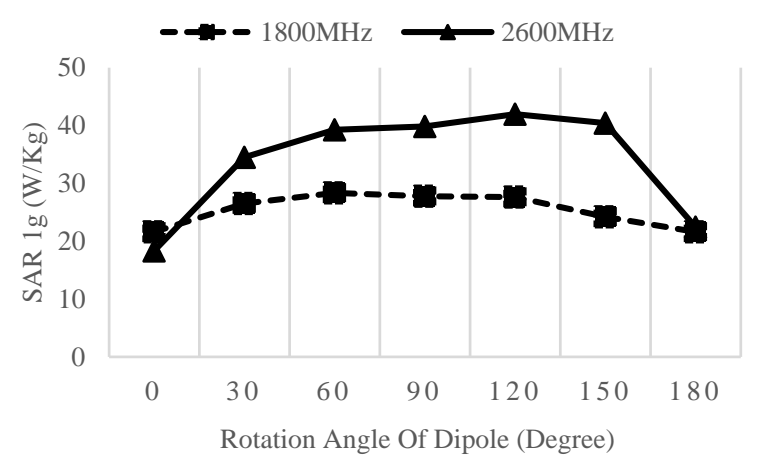

Figure 3. The maximum $\mathrm{SAR}_{1 \mathrm{~g}}$ as a function of dipole's antenna's rotation angle 
for both $1800 \mathrm{MHz}$ and $2600 \mathrm{MHz}$

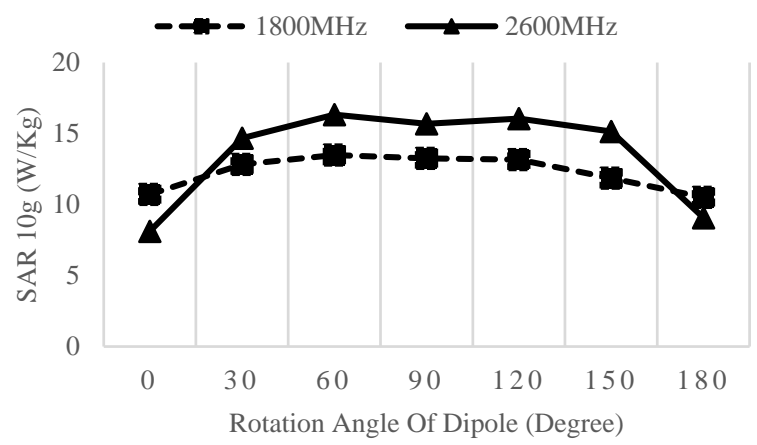

Figure 4. The maximum $\mathrm{SAR}_{10 \mathrm{~g}}$ as a function of dipole's antenna's rotation angle for both $1800 \mathrm{MHz}$ and $2600 \mathrm{MHz}$

It should be noted that in this paper, the SAR values with the dipole sources are higher than allowed in the standards. This is partly due to all the simulations were normalized to 1 Watt output power with halfwave dipole antennas.

\section{CONCLUSION}

The SAM phantom head has been used in this paper which is the standard head for SAR investigation. The RF sources was $1800 \mathrm{MHz}$ and $2600 \mathrm{MHz}$ frequency with half-wave dipole antennas. This paper has shown how the SAR in the head can be effected by frequency and polarization. It can be seen that cell phone usage near to human ear, can be lead to risk of human health. The main of this research is to study the effect of cell phones usage near to human ear can be effected by the SAR absorption with different frequency and polarization.

In conclusion, the result shows the maximum SAR that obtain is much higher than standard limit value which is $1.6 \mathrm{~W} / \mathrm{Kg}$ and $2 \mathrm{~W} / \mathrm{Kg}$ over for $1 \mathrm{~g}$ of tissue and $10 \mathrm{~g}$ of tissue respectively. The investigation will proceed with metal-embedded in ear prosthesis exposure to $4 \mathrm{G}$ signals.

\section{ACKNOWLEDGEMENTS}

In this project, the financial support by the Fundamental Research Grant Scheme (FRGS), FRGS/1/2016/TK04/UNIMAP/02/2.

\section{REFERENCES}

[1] P. Bernardi, et al., "SAR Distribution and Temperature Increase in an Anatomical Model of the Human Eye Exposed to the Field Radiated by the User Antenna in a Wireless LAN," vol/issue: 46(12), pp. 2074-2082, 1998.

[2] K. Stergiou, et al., "Effects of metallic semi-rimmed spectacles on SAR in the head from a 900MHz frontal dipole source," pp. 721-724, 2009.

[3] C. J. P. and J. C. V. W. G. Whittow, R. M. Edwards, "Effect of tongue jewelery and orthodontist metallic braces on the SAR due to mobile phones in different anatomical human head models including children," pp. 293-296, 2008.

[4] J. S. Rahhal, "Mobile Phone Antenna with Reduced Radiation into Inner Ear," pp. 474-484, 2014.

[5] M. H. Mat, et al., "Correlation Analysis on the Specific Absorption Rate ( SAR ) between Metallic Spectacle and Pins Exposed from Radiation Sources," pp. 452-455, 2012.

[6] A. Furelos, et al., "An Experimental Multi-Frequency System For Studying Dosimetry and Acute Effects on Cell and Nuclear Morphology in Rat Tissues,” vol. 129, pp. 541-558, 2012.

[7] J. Cooper and V. Hombach, "Increase in specific absorption rate in human heads arising from implantations," vol/issue: 32(24), pp. 2217-2219, 1996.

[8] P. Dimbylow and S. Mann, "SAR calculations in an anatomically realistic model of the head for mobile communication transceivers at 900MHz and 1.8-GHz," vol. 1537, 1994.

[9] N. S. and L. M. M. H. Mat, et al., "The infuence of human head model wearing metal-frame spectacles to the changes of SAR and antenna gain: simulation of frontal face exposure," 2013.

[10] W. G. Whittow and R. M. Edwards, "A Study of Changes to Specific Absorption Rates in the Human Eye Close to Perfectly Conducting Spectacles Within the Radio Frequency Range 1.0 to 3.0Ghz," 52(12), pp. 3207-3212, 2004. 
[11] W. G. Whittow, et al., "Changes in specific absorption rate in the head due to metallic gap loops and a simulated mobile phone source in a study of the effects of jewellery," 2008 Loughbrgh. Antennas Propag. Conf. LAPC, vol. 1, pp. 197-200, 2008.

[12] W. G. Whittow, et al., "The energy absorbed in the human head due to ring-type jewelry and face-illuminating mobile phones using a dipole and a realistic source," IEEE Trans. Antennas Propag., vol/issue: 56(12), pp. 38123817, 2008.

[13] S. R. A. Mutalik, et al., "A Study Effect of Specific Absorption Rate in Human Head Model due to Electromagnetic Exposure," J. Telecommun. Electron. Comput. Eng., vol/issue: 10(1), pp. 33-36, 2017.

[14] M. H. Mat, et al., "Preliminary study of electromagnetic energy absorption in the head due to the exposure of radio frequency at 900MHz," 2012 IEEE Symposium on Computers and Informatics, ISCI 2012, pp. 228-231, 2012.

[15] A. Amjad, et al., "Power Deposition Inside a Phantom for Testing of MRI Heating," vol/issue: 41(10), pp. 41854187, 2005.

[16] S. A. Mohsin, "A simple EM model for determining the scattered magnetic resonance radiofrequency field of an implanted medical device," vol. 14, pp. 1-14, 2010.

[17] L. Catarinucci and L. Tarricone, "New algorithms for the specific absorption rate numerical evaluation based on spherical averaging resonator antenna," vol. 44, pp. 427-445, 2012.

[18] S. A. Mohsin and N. M. Sheikh, "MRI Induced Heating Of Deep Brain Stimulation Leads : Effect Of The AirTissue Interface," pp. 81-91, 2008.

[19] M. Zhang and A. Alden, "Calculation of Whole-body SAR From A 100MHz Dipole Antenna," vol. 119, pp. 133$153,2011$.

[20] V. Lancellotti, et al., "Scattering from large 3-D piecewise homogeneous bodies through linear embedding via green's operators and Arnoldi basis functions," pp. 305-322, 2010.

[21] S. A. Mohsin, "Concentration of the specific absorption rate around deep brain stimulation electrodes during mri," vol. 121, pp. 469-484, 2011.

[22] M. R. I. Faruque, et al., "Design analysis of new metamaterial for EM absorption reduction," vol. 124, pp. 119$135,2012$.

[23] R. Otin, "Numerical study of the thermal effects induced by a RFID antenna in vials of blood plasma," vol. 22, pp. 129-138, 2011.

[24] K. Yanase and A. Hirata, "Effective resistance of grounded human forwhole-body averaged SAR estimation at resonance frequencies," vol. 35, pp. 15-27, 2011.

[25] R. Ikeuchi, et al., "SAR and radiation characteristics of a dipole antenna above different finite EBG substrates in the presence of a realistic head model in the $3.5 \mathrm{GHz}$ band," vol. 44, pp. 53-70, 2012.

[26] A. Andujar, et al., "Human head interaction over ground plane booster antenna technology: Functional and biological analysis," vol. 41, pp. 153-185, 2012.

[27] A. M. Montaser, et al., "An interaction study between pifas handset antenna and a human hand-head in personal communications," vol. 37, pp. 21-42, 2012.

[28] M. H. Mat, et al., "A comparative study of simple geometrical head phantoms on specific absorption rates for simulations and measurements at 900MHz," 2012 Int. Conf. Biomed. Eng. ICoBE 2012, pp. 330-334, 2012.

[29] M. H. Mat, et al., "Analysis of the correlation between antenna gain and SAR Levels inside the human head model at 900MHz," cccc2012 Asia-Pacific Symp. Electromagn. Compat. APEMC 2012 - Proc., pp. 513-516, 2012.

[30] M. S. Zulkefli et al., "Effects of shell and body tissue simulating liquid (BTSL) thickness on capsule antenna performance," ISCAIE 2012 - 2012 IEEE Symp. Comput. Appl. Ind. Electron., pp. 237-241, 2012.

[31] M. H. Mat, et al., "Effects of the metallic spectacles with braces added on Specific Absorption Rate (SAR) exposed to frontal radiation sources," LAPC 2011 - 2011 Loughbrgh. Antennas Propag. Conf., vol. 2, pp. 6-9, 2011.

[32] T. Yelkenci and S. Paker, "SAR Changes in a Human Head Model for Plane Wave Exposure ( $500-2500 \mathrm{MHz})$ and a Comparison SAR $\mathrm{C}$ hanges in a $\mathrm{H}$ uman $\mathrm{H}$ ead $\mathrm{M}$ odel for $\mathrm{P}$ lane $\mathrm{W}$ ave E xposure $(500-2500 \mathrm{MH} \mathrm{z})$ and a C omparison with IEEE 2005 S afety L imits," vol. 7823, 2017.

[33] ICNIRP, "Guidelines for limiting exposure to time-varing electric, magnetic, and electromagnetic fields ( up to 300GHz)," Health Phys., pp. 494-522, 1998.

[34] F. Moglie, et al., "Modeling of the human exposure inside a random plane wave field," vol. 29, pp. 251-267, 2011.

[35] S. H. Ronald, et al., "Designing asian-sized hand model for SAR determination t GSM900/1800:Simulation part," vol. 129 , pp. 439-467, 2012

[36] E. A. Attaro, et al., "Field synthesis in inhomogoneous media: Joint control of polarization, uniformity and SAR in MRI B-feild," vol. 118, pp. 355-377, 2011.

[37] D. Aydin, et al., "Mobile Phone Use and Brain Tumors in Children and Adolescents: A Multicenter Case-Control Study," JNCI J. Natl. Cancer Inst., vol/issue: 103(16), pp. 1264-1276, 2011.

[38] D. Goik, et al., "Modeling of the Absorption of the Electromagnetic Wave Energy in the Human Head Induced by Cell Phone," pp. 1079-1084, 2014.

[39] M. H. Mat, et al., "Ear prosthesis evaluation: specific absorption rate levels in the head due to different angles and frequencies of electromagnetic exposure," J. Electromagn. Waves Appl., vol/issue: 29(4), pp. 514-524, 2015.

[40] IEEE, "IEEE Standard for Safety Levels With Respect to Human Exposure to Radio Frequency Electromagnetic Fields, $3 \mathrm{kHz}$ to $300 \mathrm{GHz}$," vol. 2005, 2006. 


\section{BIOGRAPHIES OF AUTHORS}

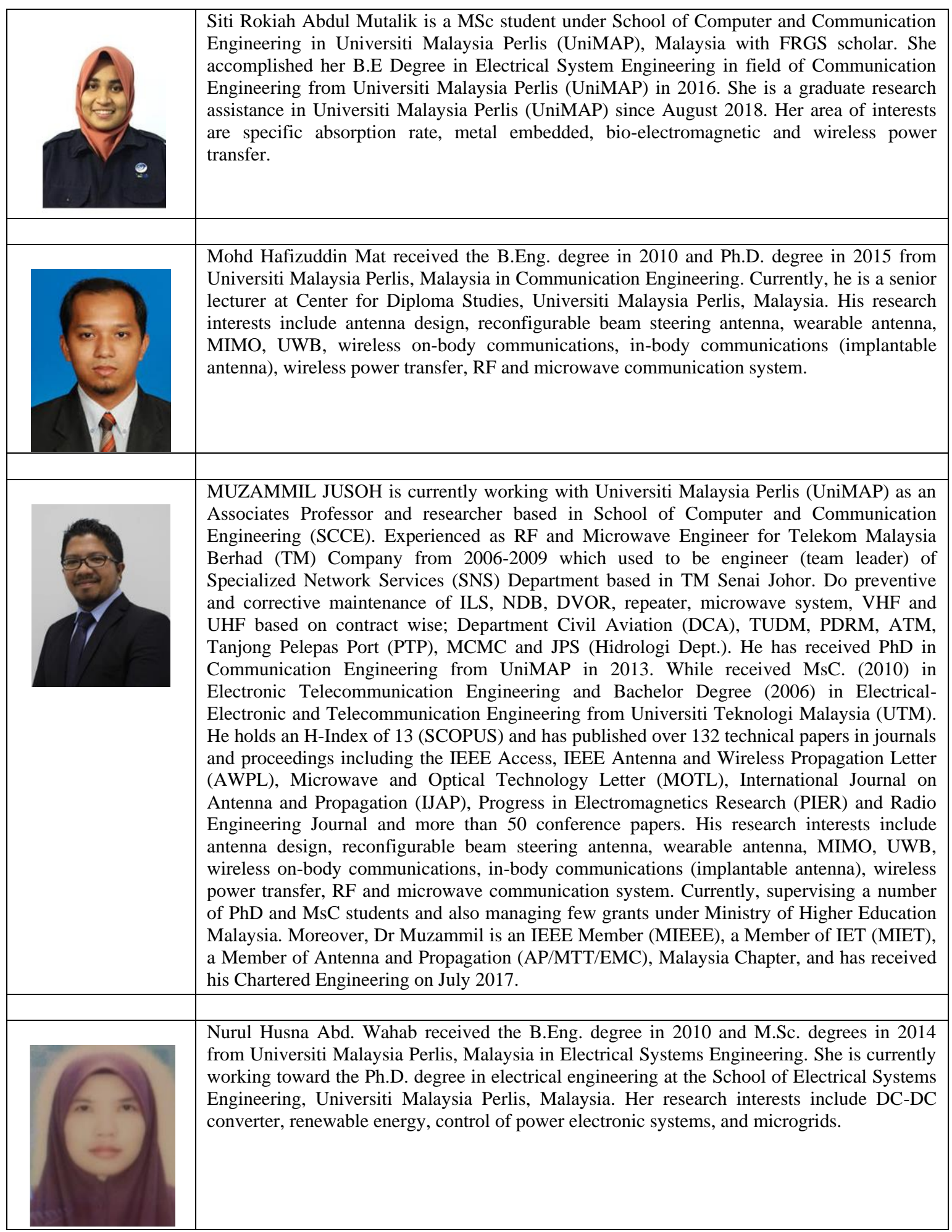

